\title{
Development and evaluation of bio-nanoparticles as novel drug carriers for the delivery of Selegiline
}

\author{
*Laxmi Goswami ${ }^{1}$, N.V. Satheesh Madhav² and Kumud Upadhyaya ${ }^{3}$ \\ ${ }^{1}$ Research Scholar, Uttarakhand Technical University, Dehradun, India \\ ${ }^{2}$ DIT University, Faculty of Pharmacy, Mussoorie Diversion Road, Dehradun, India \\ ${ }^{3}$ Department of Pharmacognosy, Kumaun University, Bhimtal, India
}

\begin{abstract}
The purpose of the present study was to formulate and evaluate Selegiline loaded bio-nanoparticles for effective treatment of Depression. For the preparation of bio-nanoparticles biomaterial was isolated from fruits of Luffa acutangula by an economic method. The biomaterial recovered from the concentrate was subjected for various physicochemical properties like color, solubility, color changing point and chemical test. Bio-nanoparticles were prepared by modified solvent evaporation method in different batches with variable drug/biomaterial ratio. Prepared batches were subjected for various evaluation studies like particle size, zeta potential, SEM, TEM, surface entrapment, in-vitro diffusion, DSC and stability. Particle size and zeta potential result revealed that all nanoformulation were within range of 110 to 152.7 with slight negative in charge. SEM and TEM study report indicate that formulations were spherical in shape with less or no aggregation. Less surface entrapment leads to better drug entrapped inside nanomatrix. Bio-nanoformulations were capable of releasing the drug in a slow sustained manner. From the present investigation, it may be concluded that biomaterial isolated from fruits of Luffa acutangula used in the preparation of bio-nanoparticle act as an efficient carriers for deliver selegiline at a controlled rate. It may significantly improve the ability to cross blood-brain barrier and serve as an effective tool to treat Depression disease.
\end{abstract}

Key Words: Modified solvent evaporation method, SEM, TEM, DSC, In-vitro diffusion study, Stability study.

\section{INTRODUCTION}

Depression is the most common of the affective disorders (defined as disorders of mood rather than disturbances of thought or cognition); it may range from a very mild condition, bordering on normality, to severe (psychotic) depression accompanied by hallucinations and delusions (Rang et al., 2003). Depression is one of the most common psychiatric disorders with a life time prevalence of $10-20 \%$ in the general population and women being at twice the risk of developing depression compared to men (Kessler et al., 2007). Literature suggests that prevalence of depression is higher in patients with chronic illnesses (Katon, 2003). Most of the drugs intended for treatment of depression enhance the availability of monoamines at the synapse by inhibiting their neuronal uptake or inhibiting their intraneuronal metabolism or increasing their release by blocking the alpha-2 auto and hetero-receptors on the monoaminergic neuron (Nutt, 2008). However the efficacy of antidepressant is often limited by their potential to reach the brain i.e., site of therapeutic action, blood brain barrier (BBB) and blood-cerebrospinal fluid (CSF) barrier restrict the transport of drugs from systemic circulation into the central nervous system (CNS) (Kilts, 2003). It is estimated that more than $98 \%$ of the small new molecules do not cross the BBB, and hence fail to achieve the therapeutic concentration within the brain parenchyma cells (Mori et al., 1995). Many approaches have been developed to circumvent this problem using liposomes (Shuting et al., 2010) magnetic nanoparticles (Zara et al., 2002) solid lipid nanoparticles and polymeric nanoparti-

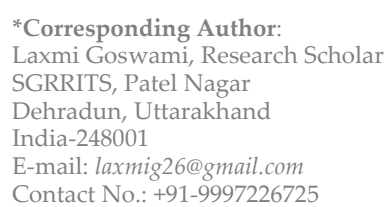

cles. The application of nanotechnology for the drug delivery to the brain opens the doors of opportunities for the formulation scientists for the better and selective brain delivery of existing and newer potential molecules with CNS activity. It has been assumed that the delivery to brain of majority of the potential CNS drugs which have inability to cross BBB could be modified by Nanotechnology in order to achieve better therapeutic action and better patient compliance (Joseph and Saha, 2013)). Selegeline is a mono amine oxidase inhibitor that is helpful in treating atypical depression and symptoms such as overeating, excessive sleeping and extreme sensitivity to rejection by others.

EMSAM, the transdermal form of selegeline, is the only transdermal medication used to treat depression. In this present study, Selegiline loaded bio-nanoparticles were prepared by using biomaterial isolated form fruits of Luffa acutangula belonging to family Cucurbitaceae which may effectively cross BBB and increase drug concentration at its site of action and serve as an effective tool to treat depression.

\section{MATERIALS AND METHODS}

Selegiline was a gift sample from Actavis (Chennai, India). The fresh fruits of Luffa acutangula were collected from plants growing in local area of Dehradun, India. Acetone was procured from SD fine chemicals (Mumbai, India). All other chemicals used were of analytical grade.

\section{Isolation and characterization of biomaterial}

Initially fruit pulp of Luffa acutangula was separated, skin was removed and minced with double distilled water and filtered and the filtrate was centrifuged at $4000 \mathrm{rpm}$ for 5 min. the supernatant was then treated with acetone and set for refrigeration at $4^{\circ} \mathrm{C}$ for 4-6 hours. The bio-material was collected by centrifugation and kept in dessicator for 
24 hours. After that the biomaterial was dried and passed through the sieve 100 . The isolated biomaterial was subjected for various physicochemical tests like colour, odour, solubility, colour changing point etc.

\section{Preparation of bio-nanoparticles}

The nanoparticles were formulated by modified solvent evaporation method (Mainardes and Evangelista, 2005; Mainardes et al., 2012). Briefly, accurate quantity of biomaterial was dissolved in $10 \mathrm{ml}$ water and sonicated for 3 cycles (1min each), the solution was marked as solution A. Different solution of drug (specified amount) and ethanol was prepared and marked as solution $\mathrm{B}$. The solution A was added to solution B through a capillary with constant stirring. This solution was evaporated at 30$35^{\circ} \mathrm{C}$ until the solution became turbid and then sonicated again. The resulting solution was then centrifuged at $28621 \mathrm{~g}$ for $20 \mathrm{~min}$. The nanoparticles obtained were collected and washed with water and dried at room temperature. Five different batches of bio-nanoparticle were prepared by varying the concentration of biomaterial. Different composition batches were shown in table 1.

\section{Characterization of bio nanoparticles}

Particle Size distribution and Surface charge determination The particle size and size distribution of the drug loaded nanoparticles was characterized by photon correlation spectroscopy (PCS) using a Zetasizer 2000 Malvern Instruments, UK. Nanopreparation was diluted with filtered $(0.22 \mu \mathrm{m})$ ultra-pure water and analyzed using Zeta sizer. The surface charge determination was performed using an aqueous dip cell in an automatic mode by placing diluted samples (with ultra-purified water) in the capillary measurement cell and cell position was adjusted (Lampercht et al., 2005).

\section{Scanning electron microscopic studies (SEM)}

The external morphology of nanoparticles was analyzed by scanning electron microscopy (SEM). The nanoparticles were fixed on supports, and coated with gold under an argon atmosphere using a gold sputter module in a high-vacuum evaporator. Samples were then observed with the scanning electron microscope at $200 \mathrm{kV}$ (W. Zheng et al., 2010).

\section{Transmission Electron microscopy (TEM)}

A drop of nanosuspension was placed on a carbon film coated copper grid for TEM. The studies were performed at $80 \mathrm{kv}$ using JOEL JEM 2100, Japan equipped with a selected area electron diffraction pattern (SAED) (Dandagi et al., 2011).

\section{Surface entrapment and drug content}

Surface entrapment and drug content study was performed by centrifugation method. Accurate quantity of nanoparticles was taken in centrifuge tube with $10 \mathrm{ml}$ of phosphate buffer $\mathrm{pH}$ 7.4. The amount of drug presented in clear supernatant after centrifugation for $30 \mathrm{~min}$ at $12,500 \mathrm{rpm}$ was determined by UV spectroscopy. The amount of drug in supernatant was then subtracted from the total amount of drug added during preparation of nanoparticle $(\mathrm{W})$. Effectively $(\mathrm{W}-\mathrm{w})$ will give the amount of drug entrapped (Dandagi et al., 2011).

\section{Differential scanning calorimetry (DSC)}

DSC was performed by Perkin Elmer JADE DSC instrument. DSC scan for drug and drug with bio-material was recorded at heating rate of $10^{\circ} \mathrm{C} / \mathrm{min}$ in temperature range $30-300^{\circ} \mathrm{C}$ under flow rate of nitrogen at $20 \mathrm{ml} / \mathrm{min}$ (Allemann et al., 1993).

\section{In vitro drug diffusion studies}

Dialysis membrane diffusion technique was used to study in-vitro diffusion of drug from the prepared bionanoparticle formulations. The receptor medium used was freshly prepared phosphate buffer $\mathrm{pH}$ 7.4. Dialysis membrane (Molecular weight cut off- $>12,000$, Hi media) previously soaked overnight in the receptor medium was on the Franz's Diffusion cell assembly. Prepared formulation was placed in the donor compartment and the assembly was kept on the multi station diffusion study apparatus (make Orchid Scientific) at $37 \pm 2^{\circ} \mathrm{C}$ and stirred at $700 \mathrm{rpm}$. Aliquots of $1 \mathrm{ml}$ were withdrawn at predetermined time intervals and immediately replaced by same volume of the fresh medium. The aliquots were suitably diluted with the dissolution medium and analyzed by UV-Vis Spectrophotometer at appropriate wavelength. The data obtained from the in vitro diffusion studies were fitted to various kinetic equations to find out the mechanism of drug release from the bio-nano formulation.

\section{Stability studies}

Stability studies of prepared nanoparticles were carried out, by storing optimized formulation at $4 \pm 1^{\circ} \mathrm{C}$ and $30 \pm 2^{\circ} \mathrm{C}$ in stability chamber for 90 days. The samples were analyzed at $0,1,2$ and 3 months for their drug content, drug release rate $\left(\mathrm{t}_{50} \%\right)$ as well as any changes in their physical appearance (ICH Q1A (R2) 2003) (Banerjee et al., 2002).

Table 1: Composition table of prepared drug loaded nanoparticles using Luffa acutangula

\begin{tabular}{|c|c|c|}
\hline \multirow{2}{*}{ S1. No. } & \multirow{2}{*}{ Ingredient } & Quantity Used \\
\hline & & SLA1 SLA2 SLA3 SLA4 SLA5 \\
\hline 1 & Selegiline & $10 \mathrm{mg} 10 \mathrm{mg} 10 \mathrm{mg} 10 \mathrm{mg} 10 \mathrm{mg}$ \\
\hline 2 & Luffa acutangula & $10 \mathrm{mg} 20 \mathrm{mg} 30 \mathrm{mg} 40 \mathrm{mg} 50 \mathrm{mg}$ \\
\hline 3 & Methanol & $5 \mathrm{ml} 5 \mathrm{ml} 5 \mathrm{ml} 5 \mathrm{ml} 5 \mathrm{ml}$ \\
\hline 4 & Water & $10 \mathrm{ml} 10 \mathrm{ml} 10 \mathrm{ml} 10 \mathrm{ml}$ \\
\hline
\end{tabular}

Table 2: Evaluation of particle size and zeta potential.

\begin{tabular}{cccc}
\hline $\begin{array}{c}\text { Formulation } \\
\text { Code }\end{array}$ & \multicolumn{2}{c}{ Particle Size } & $\begin{array}{c}\text { Zeta Potential } \\
(\mathbf{m V})\end{array}$ \\
\cline { 2 - 3 } & Size (r.nm) & Mean Intensity $\mathbf{( \% )}$ & -2.65 \\
SLA1 & 110 & 100 & -18.2 \\
SLA2 & 133 & 97.4 & -19.2 \\
SLA3 & 136.9 & 100 & -6.42 \\
SLA4 & 143.3 & 100 & -11.2 \\
SLA5 & 152.7 & 100 &
\end{tabular}

Table 3: Surface Entrapment and Drug Content study.

\begin{tabular}{cccc}
\hline Sl. No. & $\begin{array}{c}\text { Formulation } \\
\text { code }\end{array}$ & $\begin{array}{c}\text { Surface entrapment } \\
\mathbf{( m g )}\end{array}$ & $\begin{array}{c}\text { Drug Entrapped } \\
\mathbf{( \% )}\end{array}$ \\
\hline 1 & SLA1 & 1.841 & 81.59 \\
2 & SLA2 & 1.801 & 81.99 \\
3 & SLA3 & 1.786 & 82.48 \\
4 & SLA4 & 1.752 & 82.14 \\
5 & SLA5 & 1.115 & 88.85 \\
\hline
\end{tabular}


Table 4: In-vitro kinetic study.

\begin{tabular}{|c|c|c|c|c|c|c|c|}
\hline Formulation code & $\begin{array}{c}\text { Zero order } \\
\mathbf{R}^{2}\end{array}$ & $\begin{array}{c}\text { First order } \\
\mathbf{R}^{2}\end{array}$ & $\begin{array}{l}\text { Higuchi matrix } \\
\qquad \mathbf{R}^{2}\end{array}$ & $\begin{array}{c}\text { Hixson crowell } \\
\mathbf{R}^{2}\end{array}$ & $\begin{array}{c}\text { Peppas } \\
\mathbf{R}^{2}\end{array}$ & $\mathbf{N}$ & $\begin{array}{l}\text { Mechanism of } \\
\text { release }\end{array}$ \\
\hline SLA1 & 0.9753 & 0.8177 & 0.9422 & 0.9952 & 0.9054 & 1.6267 & Peppas Korsmeyer \\
\hline SLA2 & 0.9859 & 0.8327 & 0.9474 & 0.9873 & 0.9491 & 1.3378 & Peppas Korsmeyer \\
\hline SLA3 & 0.9898 & 0.8140 & 0.9458 & 0.9899 & 0.9458 & 1.3094 & Peppas Korsmeyer \\
\hline SLA4 & 0.9938 & 0.8487 & 0.9418 & 0.9773 & 0.9514 & 1.4514 & Zero order \\
\hline SLA5 & 0.9486 & 0.8425 & 0.9594 & 0.9643 & 0.9176 & 1.8223 & Peppas Korsmeyer \\
\hline
\end{tabular}

Table 5: Stability study data of formulation SLA5.

\begin{tabular}{|c|c|c|c|c|c|}
\hline \multirow{2}{*}{$\begin{array}{c}\text { Tempe- } \\
\text { rature }\end{array}$} & \multirow{2}{*}{$\begin{array}{l}\text { Evaluation } \\
\text { Parameters }\end{array}$} & \multicolumn{4}{|c|}{ Observation (Months) } \\
\hline & & $\mathbf{0}$ & 1 & 2 & 3 \\
\hline \multirow{3}{*}{$30 \pm 2^{\circ} \mathrm{C}$} & $\begin{array}{c}\text { Physical } \\
\text { appearance }\end{array}$ & - & $\begin{array}{l}\text { No } \\
\text { change }\end{array}$ & $\begin{array}{l}\text { No } \\
\text { change }\end{array}$ & $\begin{array}{l}\text { No } \\
\text { change }\end{array}$ \\
\hline & $\%$ Drug content & 72.65 & 71.54 & 71.12 & 70.76 \\
\hline & $\mathrm{t} 50 \%(\mathrm{hrs})$ & 14.03 & 13.68 & 13.57 & 13.43 \\
\hline \multirow{3}{*}{$4 \pm 1^{\circ} \mathrm{C}$} & $\begin{array}{c}\text { Physical } \\
\text { appearance }\end{array}$ & - & $\begin{array}{c}\text { No } \\
\text { change }\end{array}$ & $\begin{array}{c}\text { No } \\
\text { change }\end{array}$ & $\begin{array}{l}\text { No } \\
\text { change }\end{array}$ \\
\hline & $\%$ Drug content & 72.65 & 72.47 & 71.91 & 70.29 \\
\hline & $\mathrm{t} 50 \%(\mathrm{hrs})$ & 14.03 & 14.01 & 13.76 & 13.81 \\
\hline
\end{tabular}

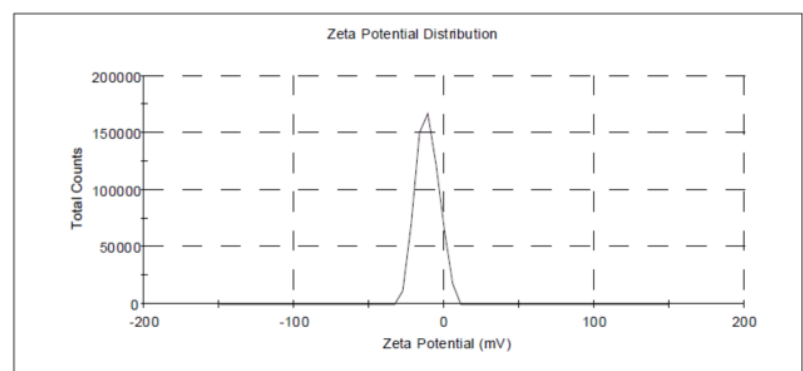

Figure 2: Zeta potential curve for Formulation SLA5.

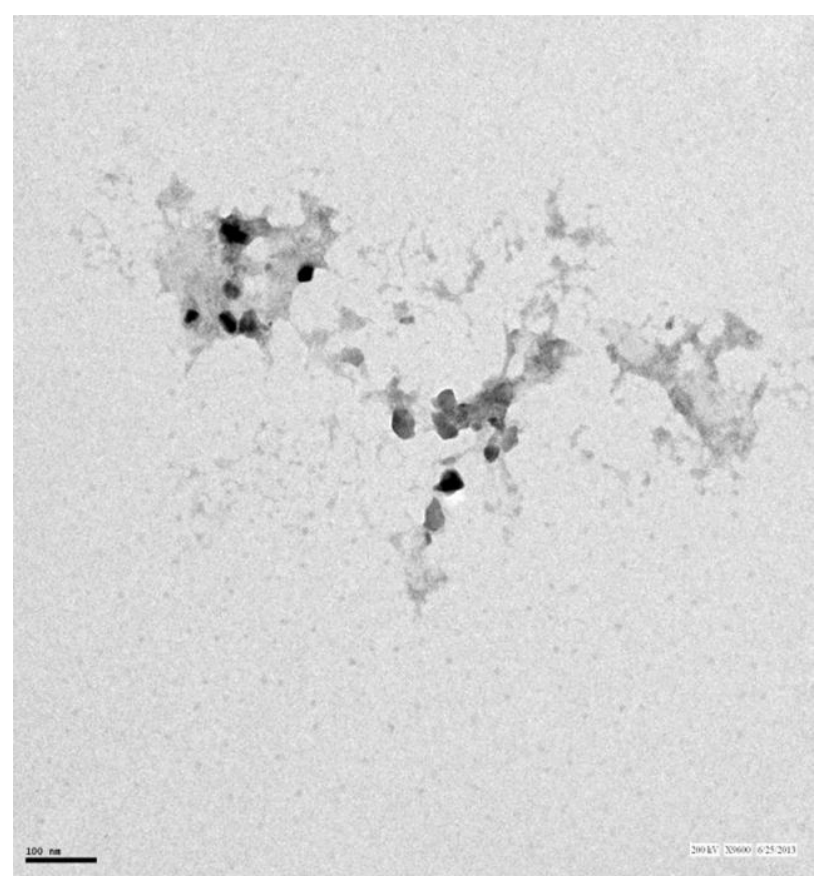

Figure 4: TEM image of Formulation SLA5.

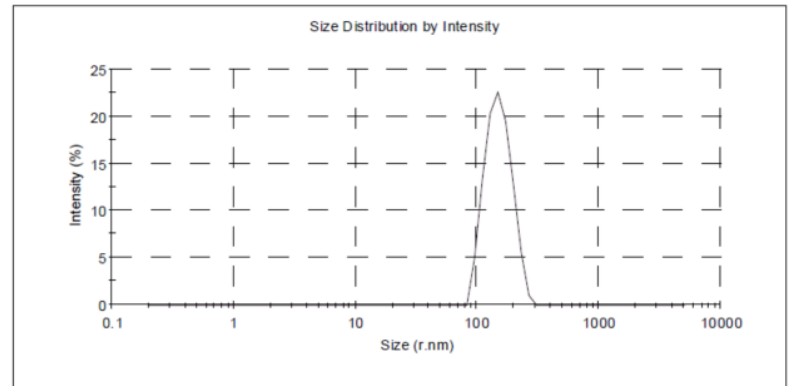

Figure 1: Particle size distribution curve for Formulation SLA5.

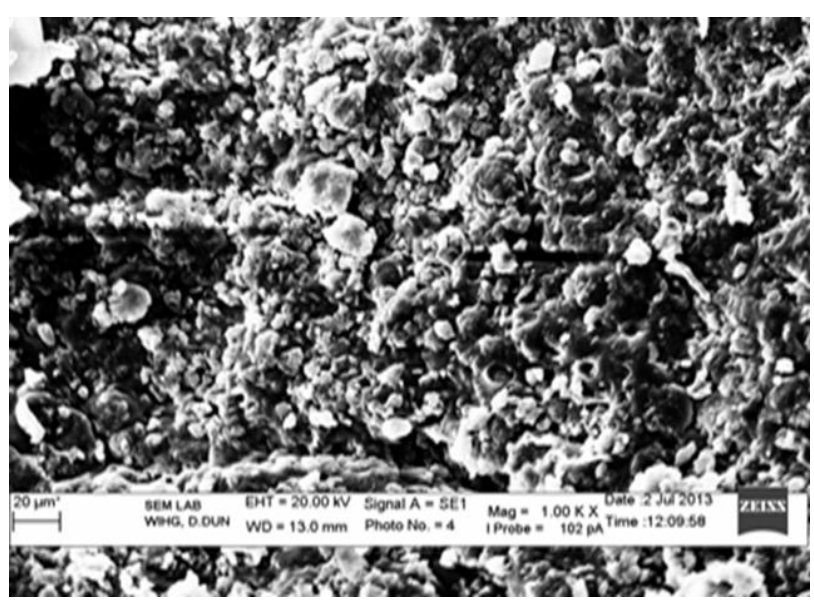

Figure 3: SEM image of Formulation SLA5.

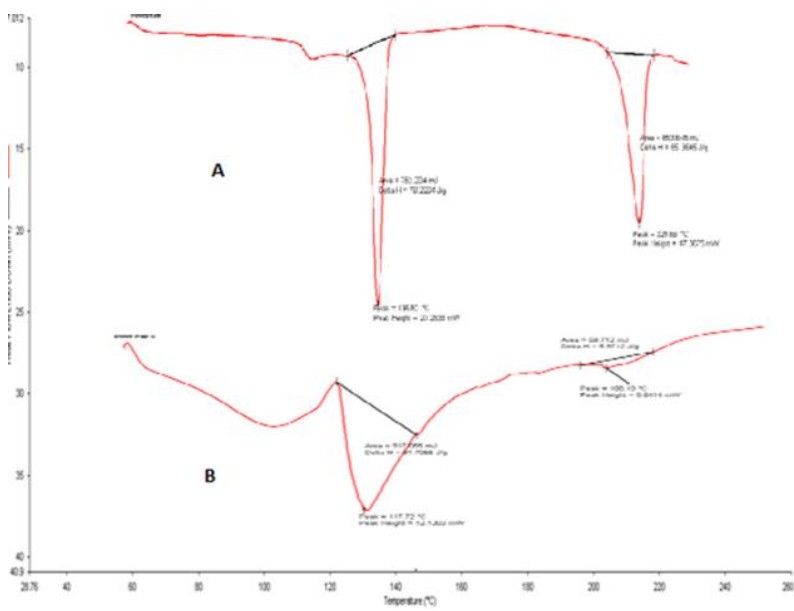

Figure 5: DSC thermograms of (A) Donepezil and (B) Donepezil loaded bio-nanoparticle formulation. 


\section{RESULTS AND DISCUSSION}

Physicochemical evaluation of isolated biomaterial

Isolated bio-material from fruits of Luffa acutangula was subjected for various evaluation parameters. Our experimental results revealed that the isolated biomaterial was brown powder with a colour changing point of $190^{\circ} \mathrm{C}$ and percentage yield $25 \%$. It was soluble in water, chloroform and insoluble in di-ethyl ether. Bionanoparticles were prepared successfully by modified solvent evaporation method. The yields of formulated nanoparticles were observed between 33 to $50 \%$. As the concentration of bio-material was increased the yield of nanoparticle was also increased.

\section{Particle size distribution and surface charge}

The particle size of drug loaded bio-nanoparticles was analyzed by Zetasizer. The Z-particle size (r.nm) of bionanoparticles formulations ranged from 110 to 152.7 as shown in table 2 . The ability of nanoparticles to alter the biodistribution and pharmacokinetics of drugs has important in vivo therapeutic applications. In this respect, the size and surface characteristics of nanoparticles are of prime importance. Nanoparticles of particle size $150 \mathrm{~nm}$ are easily captured by Kupffer cells or other phagocytic cell populations that restrict their biodistribution. Such systems prolong the duration of drug activity and also increase the targeting efficiencies to specific sites (Baumgartner et al., 2002). Particle size distribution graph (size distribution by intensity) for formulation (SLA5) is shown in figure 1. All formulations showed uniform particle size distribution. The electric charge present on the nanoparticles was evaluated by measuring the zeta potential shown in figure 2. Zeta potential of all formulated nanoparticles was in the range of -2.65 to $-19.2 \mathrm{mV}$ (table 2) which indicates moderate stability with no agglomeration.

\section{SEM Study}

SEM micrograph of optimized drug loaded bionanoparticles showed that the particles have uniform loose aggregates in spherical shape with a smooth surface and they are uniformly distributed (figure 3).

\section{TEM Study}

TEM study of nanoparticulate dispersion (figure 4) further confirms the spherical shape of nanoparticle with less or no aggregation.

\section{Surface entrapment and drug content}

Surface entrapment and drug content study result clearly revealed (table 3 ) that less amount drug was present on surface that means more amount of drug was entrapped inside the poloymeric matrix. The drug entrapment values increase with increase in biomaterial concentration.

\section{Differential scanning calorimetry (DSC)}

Thermal analysis is an important evaluation technique to find any possible interaction between the drug and used biomaterial. Any of such interaction may reduce the drug entrapment efficiency of the polymer and may also alter the efficacy of the drug. Such interaction can be identified by any change in thermogram. The thermograms of selegiline and drug loaded bionanoparticle were studied. Sharp endotherm was obtained with selegiline at $136.82^{\circ} \mathrm{C}$. Drug loaded bionanoparticle showed peak at $127.72^{\circ} \mathrm{C}$ (figure 5). All these endothermic peaks were obtained in same temperature range. This result suggests that no interaction had been taken place in bionanoparticles.

\section{In-vitro drug diffusion and kinetic study}

In-vitro diffusion study of all different five batches of drug loaded bio-nanoparticles was performed using Franz's Diffusion cell assembly. The drug release profiles from the bio-nanoparticles are shown in figure 6 . There was a sustained release of drug from all prepared nanoparticulated formulation with no burst release. Burst effect is generally associated with surface entrapment. Experimental result showed that all formulations release more than $75 \%$ of drug during 24 hours study period. Biomaterial concentration does not affect greatly on in-vitro diffusion profile of drug. Kinetic models describe drug release from immediate and modified release dosage forms. Thus the model fitting analysis (zero order, Higuchi, Hixon-Crowell, first order and KorsmeyerPeppas model) were done by comparing the coefficient of regression $\left(\mathrm{R}^{2}\right)$ values and corresponding $\mathrm{N}$ value of all the kinetic equation. The correlation coefficient $(R)$ values were used as criteria to choose the best model for the drug release from the bio-nanoparticulated formulation. From table 4 it was observed that the individual formulation having different $\mathrm{R}^{2}$ value for different model. On the basis of higher value of $\mathrm{R}^{2}$ we select the best fit model. Now Korsmeyer-Peppas Model poses great importance to know the release mechanism of the drug from the formulation. Result indicated that nanoparticles were diffusion-controlled as indicated by higher $\mathrm{R}^{2}$ values in the Higuchi model. When the release data were analyzed using the Korsmeyer-Peppas equation, the $\mathrm{n}$ values indicated that the mechanism of drug release from the bio-nanoparticles was followed supercase 2 transports. On the basis of experimental results, formulation SLA5 was selected as optimized formulation and subjected for stability study.

\section{Stability study}

Stability studies of SLA5 bio-nanoparticles were carried out, by storing optimized formulation at $4 \pm 1^{\circ} \mathrm{C}$ and $30 \pm 2^{\circ} \mathrm{C}$ in stability chamber for 90 days. The samples were analyzed at $0,1,2$, and 3 months for their drug release rate $\left(\mathrm{t}_{50 \%}\right)$, drug content as well as any changes in their physical appearance. As the experiment result revealed (table 5) no significant changes were observed in the physical appearance, drug content as well as drug release rate. These results indicated that the developed drug loaded bionanoparticles are physically and chemically stable and retain their pharmaceutical properties at various environmental conditions over a period of 3 months.

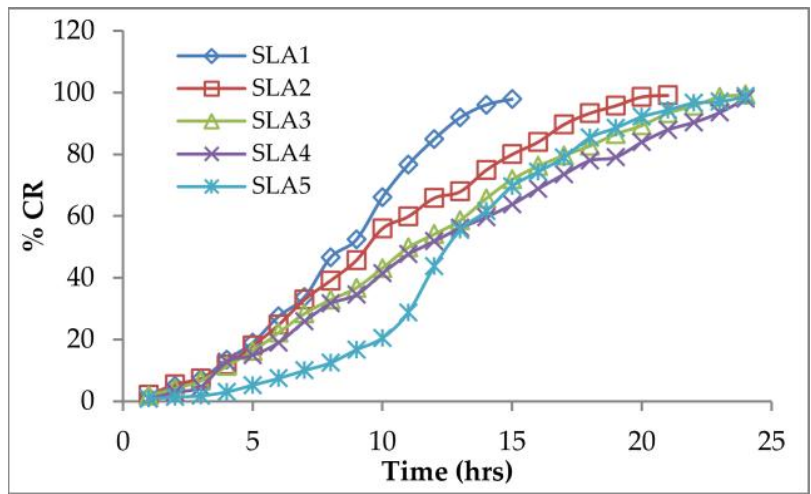

Figure 6: In-vitro Zero order release profile of formulation SLA1-SLA5. 


\section{CONCLUSION}

Selegiline loaded bio-nanoparticles were successfully prepared by modified solvent evaporation method. The concentration of biomaterial used for formulating these batches of nanoparticles showed significant effect on its efficiency to entrap Selegiline molecule. Selegiline loaded bio nanoparticles with a small size and narrow size distribution were obtained. In-vitro release study revealed that Selegiline loaded bio-nanoparticles were capable of releasing the drug in a slow sustained manner. From the present investigation, it may be concluded that biomaterial isolated from fruits of Luffa acutangula used in the preparation of bio-nanoparticle act as an efficient carriers for deliver Selegiline at a controlled rate. It may significantly improve the ability to cross blood-brain barrier and serve as an effective tool to treat Depression.

\section{REFERENCES}

Allemann E, Gurny R, Deolker E. (1993) Drug loaded nanoparticles: preparation methods and drug targeting issues. Eur I Pharm Biophar, Volume 39, Page 173-191.

Banerjee T, Mitra S, Singh AK, Sharma RK, Maitra A. (2002) Preparation and biodistribution of ultrafine chitosan nanoparticles. Int I Pharm, Volume 243, page 93-105. [DOI]

Baumgartner S, Vrecer F, and Zoroko B. (2002) Optimization of floating matrix tablets and evaluation of their gastric residence time, Int. J. Pharm, Volume 195, Page 125-135. [DOI]

Dandagi, P., Patel, P., Patil, P., Mastiholimath, V. and A. Gadad (2011) Development and characterization of a particulate drug delivery systemfor etoposide, IndianJournal of Novel Drug Delivery, Volume 3, Issue 1, Page 43-51.

Joseph, E., Saha, R.N. (2013) Advances in Brain Targeted Drug Delivery: Nanoparticulate Systems, Journal of PharmaSciTech. Volume 3, Issue 1, page 1-8.

Katon, W. J., (2003) Clinical and health services relationships between major depression, depressive symptoms, and general medical illness. Biol Psychiatry. Volume 54, Page 216-226. [DOI]

Kessler, R. C., Angermeyer, M., Anthony, J. C., et al. (2007) Lifetime prevalence and age-of-onset distributions of mental disorders in the World Health Organization's World Health Survey Initiative. World Psychiatry, Volume 6, Page168-76. PMid:18188442 PMCid:PMC2174588
Kilts, C. D. (2003) Potential new drug delivery system for antidepressants: an overview. J Clin Psychiatry, Volume 64, Page 31. PMid:14700453

Lamprecht, A., Yamamoto. H., Takeuchi, H., Kawashima, Y. (2005) Observations in simultaneous microencapsulation of 5-fluorouracil and leucovorin for combined pH-dependent release Eur J Pharm Biopharm. Volume 59, Page 367-71. [DOI]

Mainardes, R.M., Evangelista, R.C. (2005), PLGA nanoparticles containing praziquantel: effect of formulation variables on size distribution. Int $J$ Pharm. Volume 290(1-2), Page 137-144. [DOI]

Mainardes, R.M., Gremião, M.P.D. (2012) Nanoencapsulation and characterization of zidovudine on poly(L-lactide) and poly(L-lactide)poly(ethylene glycol)-blend nanoparticles. J Nanosci Nanotechnol. Volume 12. Issue 11, Page 8513-8521. [DOI]

Mori, N., Kurokouchi, A., Osonoe, K., Saitoh, H., Ariga, K., Suzuki, K., Iwata, Y. (1995) Liposome entrapped phenytoin locally suppresses amygdaloid epileptogenic focus created by db-CAMP/EDTA in rats, Brain Res, Volume 703, Page 184-190. [DOI]

Nutt, D. J. (2008) Relationship of neurotransmitters to the symptoms of major depressive disorder. J Clin Psychiatry, Volume 69, Issue 4 Ernst RL, Hay JW. The US economic and social costs of Alzheimer's disease revisited. Am J Public Health, Volume 84, Page 1261-1264.

Rang, H. P., Dale, M. M., Ritter, J. M., Moore, P. K. (2003). Drugs used in affective disorders In: Pharmacology. 5th ed. Edinburgh: Churchill Livingstone, Page 535-48.

Shuting, K., Feng, Y., Ying, W., Yilin, S., Nan, Y., Ling, Y. (2010) The bloodbrain barrier penetration and distribution of PEGylated fluoresceindoped magnetic silica nanoparticles in rat brain, Biochem. Biophys. Res, Volume 394, Page 871-876. [DOI]

Tian, X. H., Lin, X. N., Wei, F., Feng, W., Huang, Z. C., Wang, P., et al., (2011) Enhanced brain targeting of temozolomide in polysorbate-80 coated polybutylcyanoacrylate nanoparticles, Int. J. Nanomedicine, 6 , Page 445-452. PMid:21445277 PMCid:PMC3061435

Zara, G. P., Cavalli, R., Bargoni, A., Fundaro, A., Vighitto, D., Gasco, M. R. (2002) Intravenous administration to rabbits of non-stealth and stealth doxorubicin loaded solid lipid nanoparticles at increasing concentration of stealth agent: pharmacokinetics and distribution of doxorubicin in brain and in other tissues, J.Drug Target, 100, Page 327-335. [DOI]

Zheng, W., Zhao, L, (2010) Preparation and the in Vitro Evaluation of Nanoemulsion System for the Transdermal Delivery of Granisetron Hydrochloride, Chem. Pharm. Bull, Volume 58, Page 1015. [DOI] 